\title{
Assessment of the metals contamination and their grading by SAW method: a case study in Sarcheshmeh copper complex, Kerman, Iran
}

\author{
Ali Rezaei ${ }^{1} \cdot$ Mohammadreza Shayestehfar $^{2} \cdot$ Hossein Hassani $^{1} \cdot$ \\ Mohammad Reza Tavakoli Mohammadi ${ }^{3}$
}

Received: 1 July 2014/ Accepted: 26 March 2015/Published online: 10 April 2015

(c) The Author(s) 2015. This article is published with open access at Springerlink.com

\begin{abstract}
Studying the distribution of metals in the soil of mineral regions is one of the most important environmental issues. These metals are transferred to the cycle of nature by geogenic and anthropogenic resources, causing serious short- and long-term effects, and posing serious risks for the survival of living organisms. Various mining activities, smelting and beneficiation processes are important anthropogenic factors in the presence of metals in soil, which play a far more effective role in soil pollution than natural factors. Sarcheshmeh copper mine in Kerman is one of the largest copper sulfide mines in the world, for which evaluation and grading of metals contamination has paramount importance due to the high volume of mining. In this study, in order to determine the metal content in the surface soil from the Sarcheshmeh copper complex soils area, 120 surface soil samples were taken from a depth of $30 \mathrm{~cm}$, and analyzed for the metals $\mathrm{Pb}, \mathrm{Ni}, \mathrm{Se}, \mathrm{Mo}$ and $\mathrm{Zn}$ using the ICP-MS method. Then, the contamination coefficient, enrichment factor and geoaccumulation index of these metals were calculated. Based on expert views on the relative importance of each of the indicators and their final weight, risk assessment and grading by the simple additive weighting (SAW) method was performed. According to the
\end{abstract}

Ali Rezaei

rezaei.ali169@gmail.com

1 Department of Mining and Metallurgy Engineering, Amirkabir University of Technology, Tehran, Iran

2 Department of Mining Engineering, Shahid Bahonar Kerman University, Kerman, Iran

3 Department of Mining Engineering, Tarbiat Modares University, Tehran, Iran results, the highest risk of pollution was obtained for nickel and the lowest was for selenium.

Keywords Metals - Contamination factors - SAW techniques · Sarcheshmeh copper complex

\section{Introduction}

This study is one of very few dealing with the distribution and the origin of metals in Sarcheshmeh copper complex soils area. In many industrialized countries, soil contamination has become a serious problem. Significant increases in soil metal content are found in areas of high industrial activity where accumulation may be several times higher than the average content in non-contaminated areas. Additionally, areas distant from industrial centers also show increased metal concentrations due to long-range atmospheric transport. The impact of metal pollution on ecosystems due to anthropogenic activities like smelting or mining activities has been frequently investigated (Adriano 1986; Cambier 1997; Dijkstra 1998; Sheppard et al. 2000). In industrial countries, atmospheric pollutants have affected forests and soils during the last century. Particularly, long-range atmospheric transport of metals can lead to pollutant deposition even in supposedly pristine areas (De Vries et al. 2002).

Thus, there is a considerable variation in how the impact of anthropogenic pollution on a given site is quantified. Such variation has subsequent implications for the overall assessment, monitoring and management of contaminant effects. Much of this impact relates to the dispersion of metal contamination into soils, sediments, ground and surface waters, and subsequent uptake by biota. Relating effects of contamination on the environment commonly 
requires separation of background population(s) and patterns related to natural or geogenic processes from populations or outlying values relating to the effects of mineralization or anthropogenic environmental contamination. This is particularly important in agricultural areas (Tlili-Zrelli et al. 2013).

Furthermore, knowledge of soil geochemistry is fundamental when we attempt to determine the effects stemming from an anthropogenic activity and its impact on the geoecosystems as a result of its toxicities (Albanese et al. 2007; Cicchella et al. 2008; Giaccio et al. 2012; Guillén et al. 2011, 2012). In this respect, it is essential to establish geochemical maps for chemical elements associated with different lithologies in order to distinguish if their source is geogenic or anthropogenic (Plant et al. 2001). In assessing the impact of metal pollution on mining environments, a number of different reference materials and enrichment calculation methods have been used by various workers (Salomons and Förstner 1984; Müller 1969; Hakanson 1980). In addition to the scientific or mining standpoint, geochemical maps constitute an effective tool for environmental planning (Ferguson and Kasamas 1999; Li et al. 2004). They reveal information about source, distribution, and dynamics of chemical elements. Geochemical maps include both the geogenic concentration or geochemical background (GB) value, and the concentration that is the result of anthropogenic activity (Guillén et al. 2011). This explains why GB defined by Hawkes and Webb (1962) as "the normal abundance of a chemical element in barren earth material" has become crucial in environmental studies. It was introduced to differentiate between normal and abnormal element concentration (Martínez et al. 2007). Exploratory Data Analysis (EDA) has been recommended as an effective tool to determine the GB (Zhou and Xia 2010). According to the literature, this method was tested and proven by numerous authors (Bounessah and Atkin 2003; Reimann et al. 2005).

A focused and strategic approach to assessing the ecological risk of contaminants can be effective in preventing or reducing contamination (Hayaty et al. 2014). In fact, knowing the quantity and concentration of contaminants in the soils, and recognizing and correctly ranking the risk factors associated with each, is essential for proper evaluation and an appropriate response to environmental risks to reduce down-gradient damage (Hwang and Yoon 1981).

The Sarcheshmeh Copper Mine in Iran is one of the world's largest copper sulfide mines (Hayaty et al. 2014). In this study, we determined evaluation criteria, including the contamination factor $(\mathrm{CF})$, enrichment factor $(\mathrm{EF})$, pollution load index (PLI), and geoaccumulation index $\left(I_{\mathrm{geo}}\right)$, to assess the risk of pollution from metals $(\mathrm{Pb}, \mathrm{Ni}$, $\mathrm{Se}, \mathrm{Mo}$, and $\mathrm{Zn}$ ) around the mines soils. Although it is relatively easy to assess each of these criteria, considering all of them simultaneously is more challenging. The soil contaminants in the studied area were assessed using the simple additive weighting (SAW) technique. Fuzzy techniques have been used alone or in combination with other methods in previous environmental studies (Tzeng and Hwang 2011).

\section{Materials and methodology}

\section{The study area}

The Sarcheshmeh Copper Mine is located $160 \mathrm{~km}$ southwest of Kerman Province and $50 \mathrm{~km}$ from the city of Rafsanjan (Hayaty et al. 2014). The location of the Sarcheshmeh copper complex is shown in Fig. 1.

\section{Sampling and analysis}

Special consideration was given to the used criteria to select sampling point locations. After a review of topographic and geologic maps, and according to previous studies on the Sarcheshmeh Copper Mine (Shayestehfar and Rezaei 2010), soil sampling was established in different areas. The sampling design was made to compare the concentration gradient and possible chemical element mobilization. In order to estimate the metals ratio in the surface soils of the Sarcheshmeh copper mine area and to evaluate the pollution level, 120 surface soil samples were collected up to a depth of $30 \mathrm{~cm}$.

Samples were taken within the first $30 \mathrm{~cm}$ of soil using a stainless steel shovel.

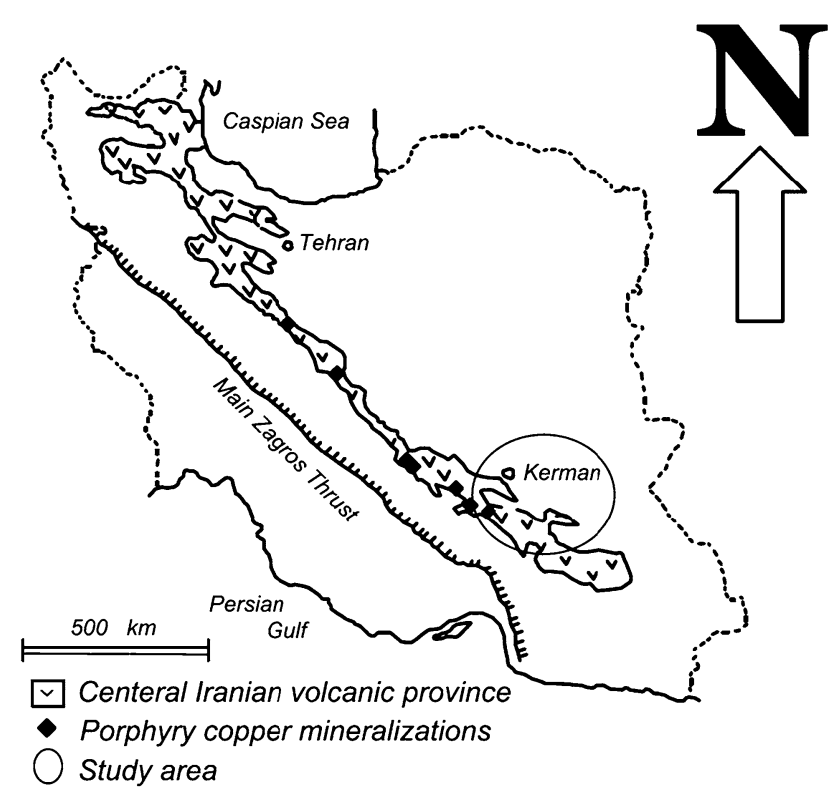

Fig. 1 Geographic location of Sarcheshmeh copper complex 
To minimize sampling errors, each sample underwent a quartering operation, and then was stored in a polyethylene bag. After this step, each sample was dried in an oven at $100{ }^{\circ} \mathrm{C}$ in the laboratory and then sieved through a $2-\mathrm{mm}$ mesh. The sample which was smaller than $2 \mathrm{~mm}$ was ground in agate mortar until it was a fraction smaller than $63 \mu \mathrm{m}$ for subsequent chemical analysis. Chemical analyses were carried out at Acme Analytical Laboratories Ltd. (Vancouver, Canada), and were analyzed for the metals of $\mathrm{Pb}, \mathrm{Ni}$, Se, Mo and $\mathrm{Zn}$ with the help of inductively coupled plasma-mass spectrometer (ICP-MS). The data quality was assessed using duplicate sample analyses, blanks, and concentration measurement accuracy estimation. The accuracy and precision of the analysis was confirmed by sending duplicate samples to the Tarbiat Modares University laboratory in Iran. The analytical precision and the accuracy were better than $\pm 5 \%$ for the analyzed elements. Figure 2 shows the location of sampling stations.

\section{Statistical analysis}

\section{Descriptive statistics}

The following statistical parameters were determined for the five considered and analyzed elements: minimum, maximum, mean for the central tendency measurement, standard deviation for the data dispersion measurement; while the data distribution was tested for normality using the Kolmogorov-Smirnov (K-S) test, (Table 1). These parameters will be helpful for comparing datasets, and subsequently summarizing the obtained results and facilitating its consequent interpretations (Burgos et al. 2005; Cai et al. 2012; Martínez et al. 2007). Figure 3 shows the histogram of the metals $\mathrm{Pb}, \mathrm{Ni}, \mathrm{Se}, \mathrm{Mo}$, and Zn.

Investigating the statistical distribution of concentrations of $\mathrm{Pb}, \mathrm{Zn}$ and Mo metals shows the abnormal distribution with positive skewness, indicating anthropogenic factors, in addition to geogenic factors and weathered rock units in the concentration of these elements in different parts of the soil. In other words, a sort of enriched earth was observed in some samples and their statistical distribution was also characterized. This fact can be interpreted from the histogram of metals. Maximum concentrations of metals $\mathrm{Pb}, \mathrm{Ni}$, Se, Mo and $\mathrm{Zn}$ samples are measured, and the result is $1124,88.7,4.8,39$ and $2652 \mathrm{mg} / \mathrm{kg}$, respectively. The average concentration of metal prevalence is: $\mathrm{Zn}>\mathrm{Pb}>\mathrm{Ni}>\mathrm{Mo}>\mathrm{Se}$.

The map of variations in the concentration of metals $\mathrm{Pb}$, $\mathrm{Ni}$, Se, Mo and $\mathrm{Zn}$ in the studied area is shown in Figs. 4, $5,6,7$ and 8 .

\section{Methods for estimating background and baseline concentration}

A crucial first step in evaluating the impact of soil pollution and the level of contamination affecting a given area is to establish a reference background or baseline sample of known metal composition. Two methods are considered. The first being the use of average crustal values as reference concentrations, and the second method seeks to establish a local baseline by analyzing comparable local soil unaffected by anthropogenic activity.

\section{Background values from average crustal concentrations}

In earlier environmental work (Salomons and Förstner 1984), a common method for comparing soil metal concentrations with precivilization background levels was to compare the present-day metal levels with their concentrations in standard earth materials such as average shale (Turekian and Wedepohl 1961) or average crustal values (Taylor 1964). Abundances of the studied metals in average continental shale and crust are presented in Table 2 .

According to Fig. 9, a comparison of the mean concentrations of potentially toxic metals in soil samples with the average crust values for uncontaminated soils and average shale shows that the higher levels of contaminated metals are $\mathrm{Pb}, \mathrm{Se}, \mathrm{Mo}$ and $\mathrm{Zn}$ compared to the average crust values. The $\mathrm{Ni}$ metal is less than the average shale. The mean average of the $\mathrm{Ni}$ element is less than the average in the shale. According to Table 2, the correlation between $\mathrm{Pb}$ and $\mathrm{Zn}$ is very high. In addition, a very good correlation between Mo and Se can be clearly recognized.

\section{Results and discussion}

\section{Determination of assessment criteria of soil risk}

The quantitative results of analysis of the studied soils indicated variable concentrations of metals, and therefore the statistical parameters listed in Table 1 were used to show their range in the sampling stations.

When the geochemical distribution of elements in the environment is due to natural and human factors, to assess the trend of changing contaminant concentration in environmental studies, factors such as contamination factor, pollution load index, enrichment factor and geoaccumulation index are used (Adama et al. 2005; Vardes et al. 2005; Reddy et al. 2004; Selvaraj et al. 2004). In this 
Fig. 2 Map of sampling stations of soils in the Sarcheshmeh copper complex
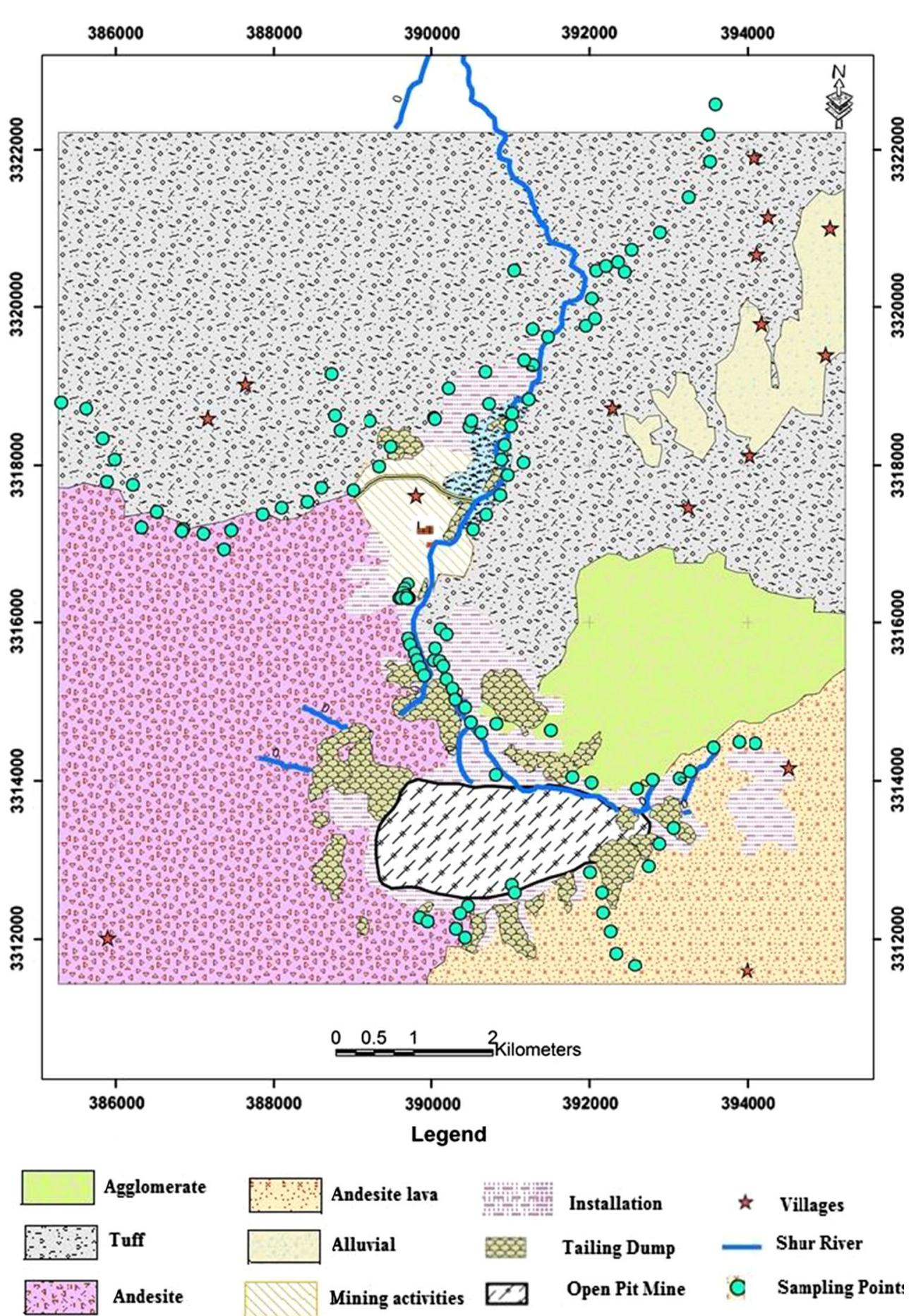

study, the above criteria were calculated for soils of Sarcheshmeh copper complex area, and were used as indicators of increases in the pollution risk caused by metals. Thus, the multi-criteria decision-making techniques such as simple additive weighting (SAW) were used to consider the combined and simultaneous effects of all the indicators for different elements, and the formulas were obtained as well.

\section{Contamination factor (CF)}

The $\mathrm{CF}$ is the ratio of the element concentration in a sample to its concentration in the background sample. $\mathrm{CF}$ values higher than 1 indicate contamination:

$\mathrm{CF}=\frac{C_{\text {Sample }}}{C_{\text {Background }}}$ 
Table 1 Descriptive basic statistics of the metals in the surficial soils of Sarcheshmeh copper complex (mg/kg)

\begin{tabular}{llrrcr}
\hline Element & Valid $N$ & \multicolumn{1}{c}{ Mean } & Maximum & Minimum & Std. dev. \\
\hline $\mathrm{Pb}$ & 120 & 127.62 & 1124.40 & 15.04 & 158.02 \\
$\mathrm{Ni}$ & 120 & 27.02 & 88.70 & 6.40 & 12.58 \\
$\mathrm{Se}$ & 120 & 1.08 & 4.80 & 0.1 & 0.81 \\
$\mathrm{Mo}$ & 120 & 7.08 & 39.80 & 0.35 & 8.11 \\
$\mathrm{Zn}$ & 120 & 252.23 & 2652.50 & 44.30 & 318.90 \\
\hline
\end{tabular}

in which $C_{\text {sample }}$ is the concentration of an element in the sample and $C_{\text {background }}$ is the concentration of that element in the background sample. The background sample is obtained by statistical methods by comparing soil samples from the region with local soils not influenced by human factors (Abrahim and Parker 2008; Adomako et al. 2008). Table 3 shows the CF for the Sarcheshmeh complex soils area.

\section{Pollution load index (PLI)}

This index is calculated using the following equation:

PLI $=\sqrt[n]{\mathrm{CF}_{1} \times \mathrm{CF}_{2} \times \mathrm{CF}_{3} \times \cdots \times \mathrm{CF}_{n}}$.

Pollution load index values higher than 1 indicate contamination and values close to one indicate similar concentrations of the contaminant in the studied sample and background sample (Adomako et al. 2008; Qishlag et al. 2007). The calculated PLI in this study was 2.49 .

\section{Enrichment factor (EF)}

In order to select chemical elements that have been enriched in the Sarcheshmeh copper mine area soils, enrichment factor (EF) was calculated (Bourennane et al. 2010; Li and Feng 2012; Martínez et al. 2007). It was widely employed to identify the anthropogenic source of metallic elements (Li and Feng 2012). Based on EF, five contamination categories were recognized: (1) $\mathrm{EF}<2$ states deficiency to minimal enrichment; (2) $2 \leq \mathrm{EF}<5$ moderate enrichment; (3) $5 \leq \mathrm{EF}<20$ significant enrichment; (4) $20 \leq$ EF $\leq 40$ very high enrichment, and; (5) EF $>40$ extremely high enrichment (Han et al. 2006; Lu et al. 2009). The EF was calculated for the chemical elements using the following generalized equation according to Chester and Stoner (1973) and Zoller et al. (1974):

$\mathrm{EF}_{\mathrm{El}}=\frac{[\mathrm{El}]_{\text {sample }} /[X]_{\text {sample }}}{[\mathrm{El}]_{\text {crust }} /[X]_{\text {crust }}}$,

where "El" is the element under consideration, the square brackets indicate concentration (usually in mass/mass units, such as $\mathrm{mg} / \mathrm{kg}$ ), " $X$ " is the chosen reference element (see below) and the subscripts "sample" or "crust"
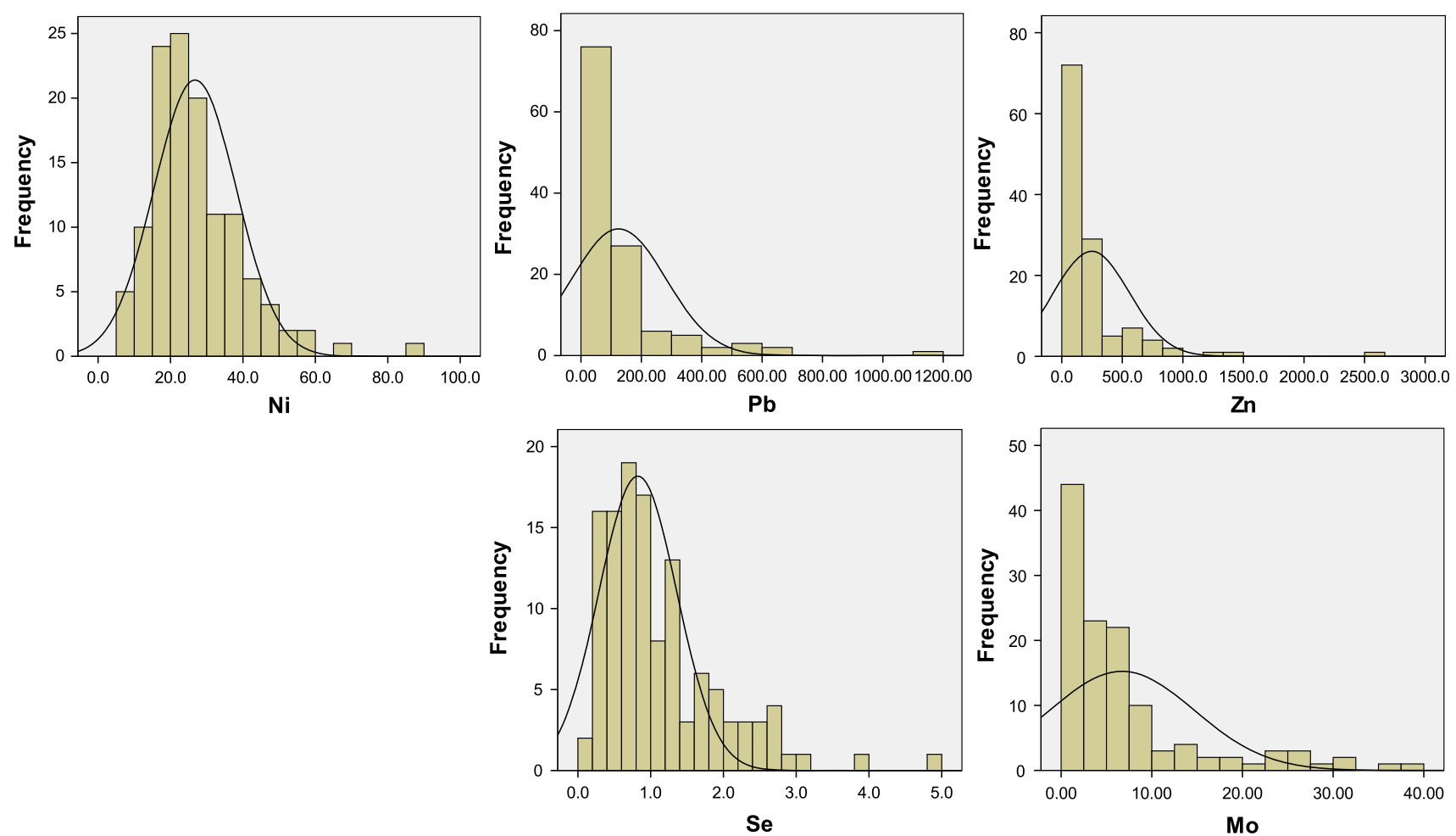

Fig. 3 Histogram of metals $\mathrm{Pb}, \mathrm{Ni}, \mathrm{Se}, \mathrm{Mo}$ and $\mathrm{Zn}$ 
Fig. 4 Map of variation in $\mathrm{Pb}$ concentrations at Sarcheshmeh copper complex

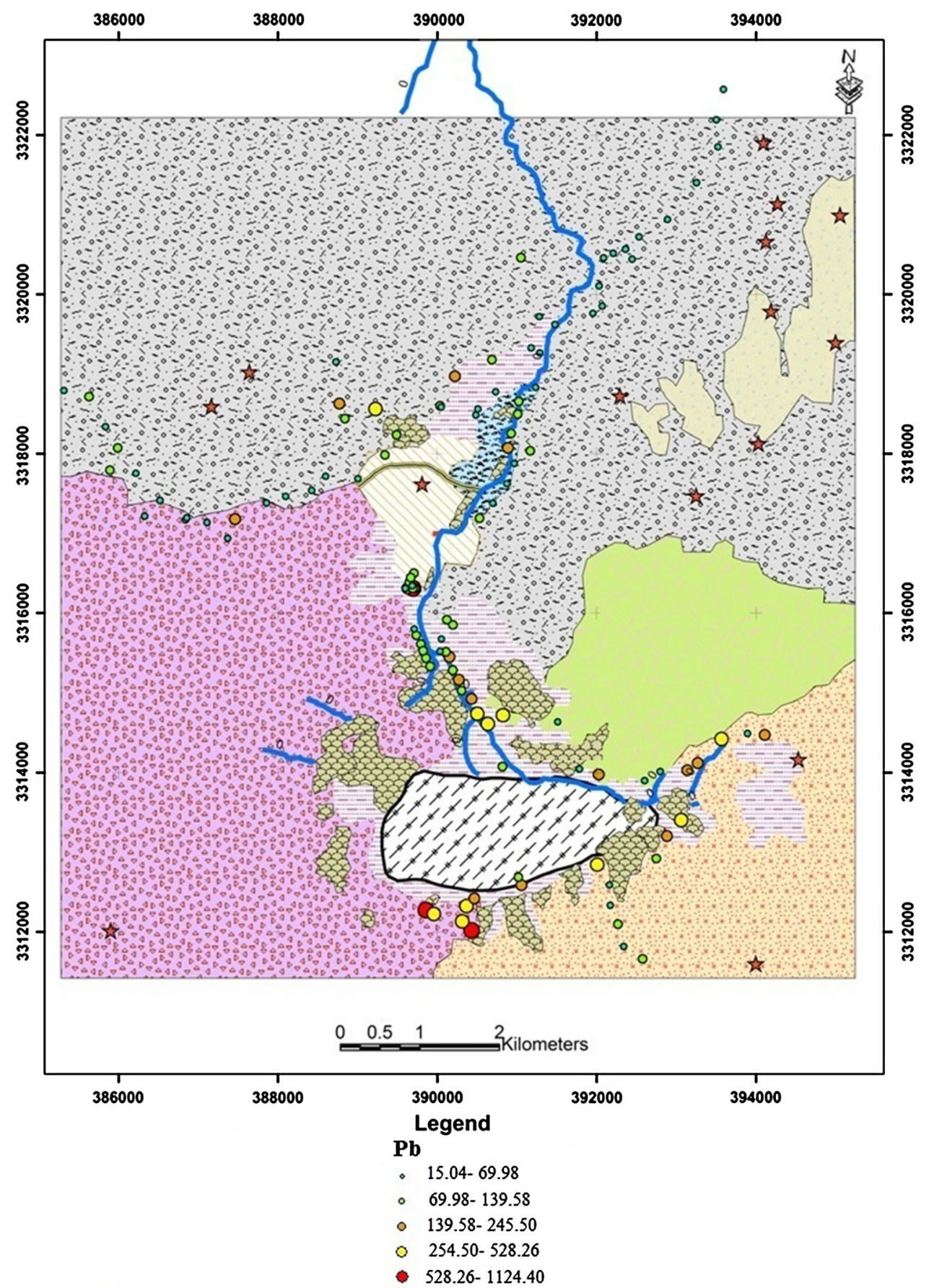

indicate which medium concentration refers to. In this study, scandinum was selected to be the reference value. Indeed, Sc is the most common reference value used to calculate the EF (Bourennane et al. 2010; Buat-Menard and Chesselet 1978; Lu et al. 2009).

Table 4 summarizes EF values which indicate how many times the measured concentrations exceed the Clarke values.

\section{Geoaccumulation index $\left(I_{\text {geo }}\right)$}

Another index used for risk assessment of metals in soils is $I_{\text {geo }}$ (also known as the Muller index), which can be expressed as (Audry et al. 2004; Bermejo Santos et al. 2003; Munendra et al. 2002; Muller 1979):

$I_{\text {geo }}=\log _{2}\left[C_{n} / 1.5 B_{n}\right]$, 

concentrations at Sarcheshmeh copper complex
Fig. 5 Map of variation in $\mathrm{Ni}$

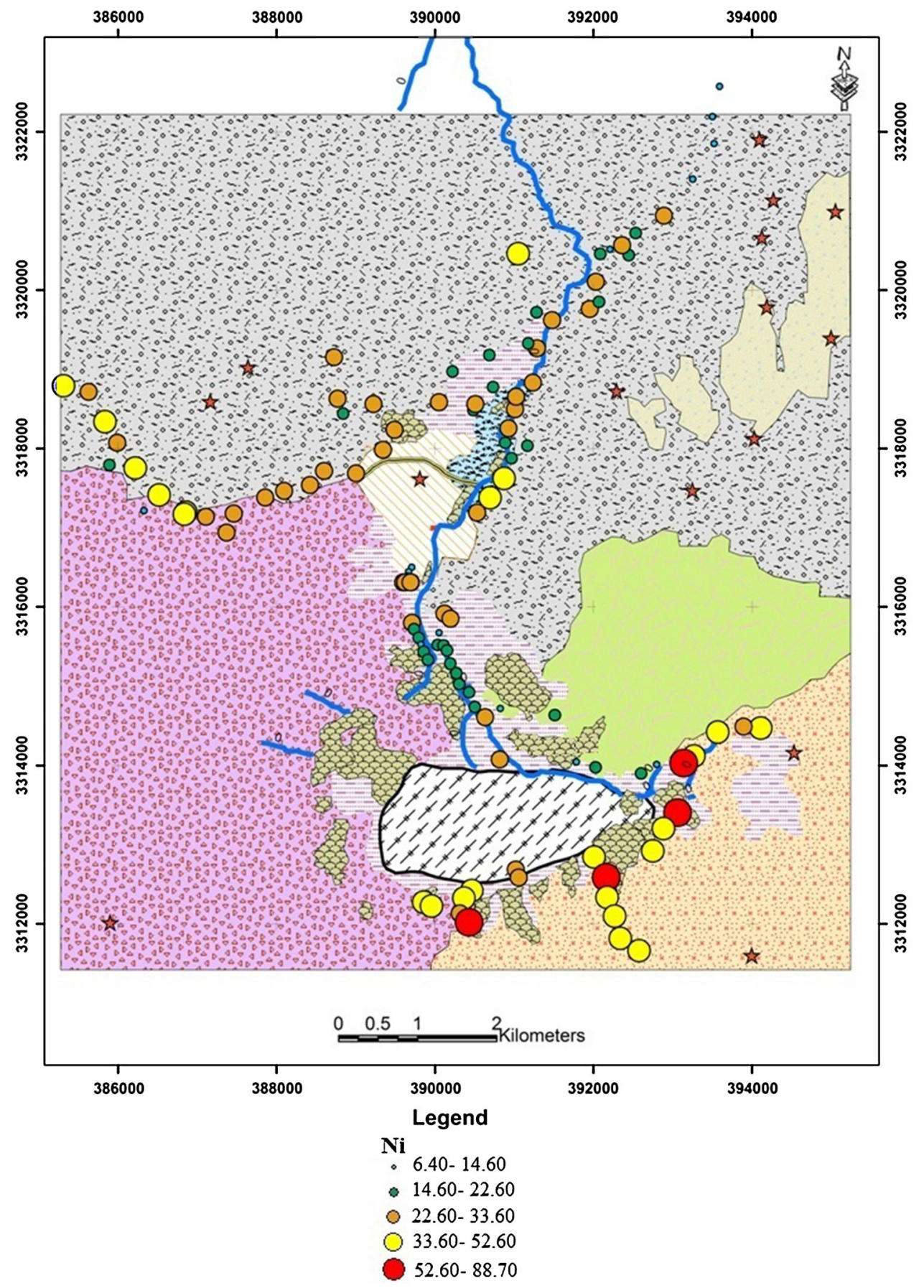

FDAHP methodology

the sample and $B n$ represents the concentration of the element in the background sample. 1.5 coefficient is used to eliminate possible changes in the background due to geological effects (Chen et al. 2007; Ghrefat and Yusuf 2006). Table 4 lists the calculated values of this index for metals in the soils and the associated pollution load to the region.

\section{Establishment of comparison matrixes}

To evaluate the risk of metal contamination and ranking them using quantitative techniques MADM, coefficient of relative importance index was calculated using experts. In order to establish the main comparison matrix using the 
Fig. 6 Map of variation in Se concentrations at Sarcheshmeh copper complex

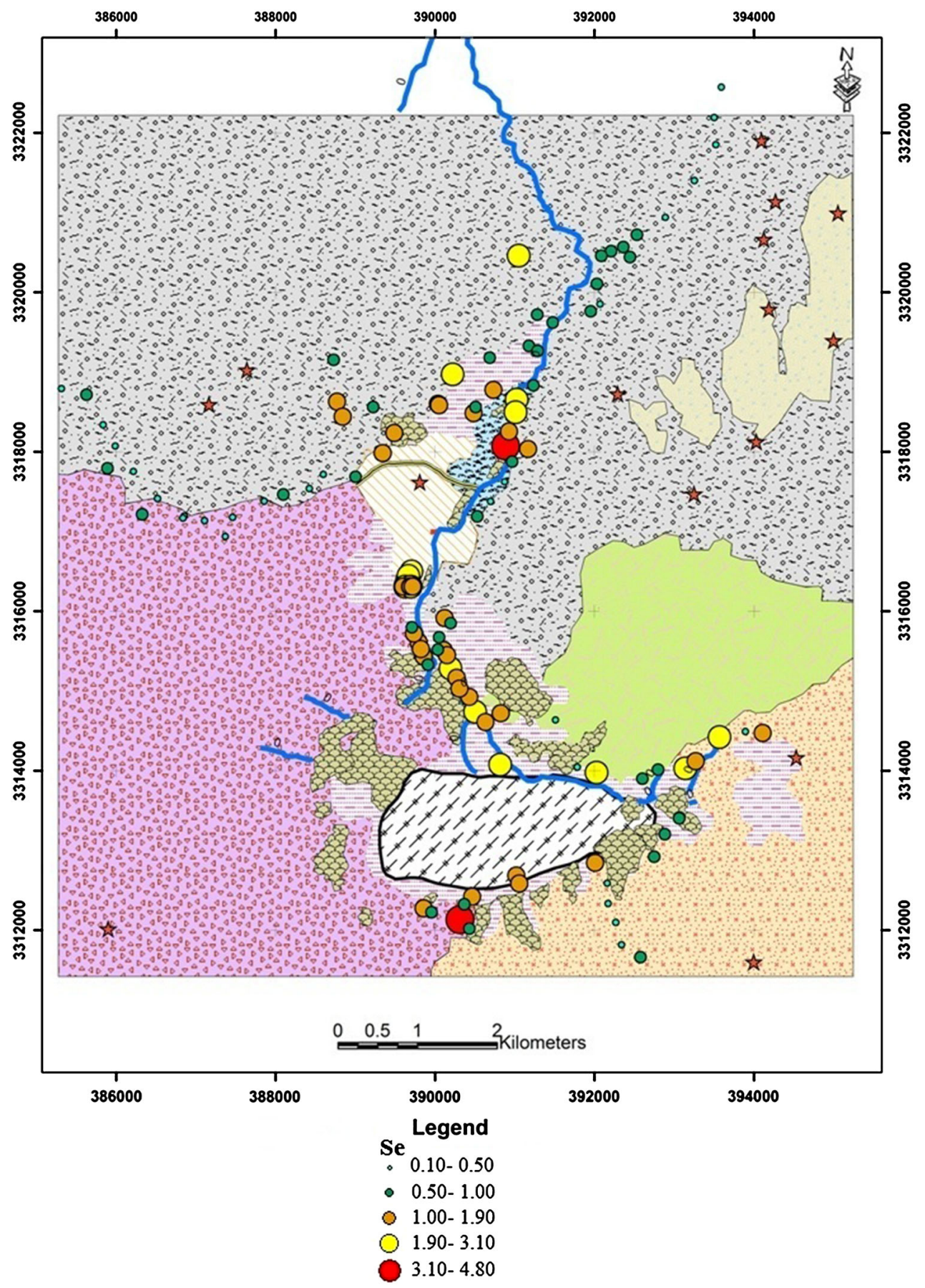

FDAHP method, it is essential to have comparison matrix of parameters based on each expert's opinion. For this purpose, technical questionnaires were prepared, based on the Saaty (1980) rating scale (Table 5).

Let $\mathrm{C}_{1}, \mathrm{C}_{2}, \ldots, \mathrm{C}_{\mathrm{n}}$ denote the set of elements, while $a_{i j}$ represents a quantified judgment on a pair of elements $C_{i}$ and $C_{j}$. The relative importance of two elements is obtained from division rate of $C_{i}$ on rate of $C_{j}$ based on the questionnaire. This yields an $n \times n$ matrix $\mathrm{A}$ as follows (Hoseinie et al. 2009):

$A=\left[a_{i j}\right]=\left[\begin{array}{cccc}1 & a_{12} & \cdots & a_{1 n} \\ 1 / a_{12} & 1 & \ldots & a_{2 n} \\ \vdots & \vdots & \ddots & \vdots \\ 1 / a_{1 n} & 1 / a_{2 n} & \cdots & 1\end{array}\right]$ 
Fig. 7 Map of variation in Mo concentrations at Sarcheshmeh copper complex

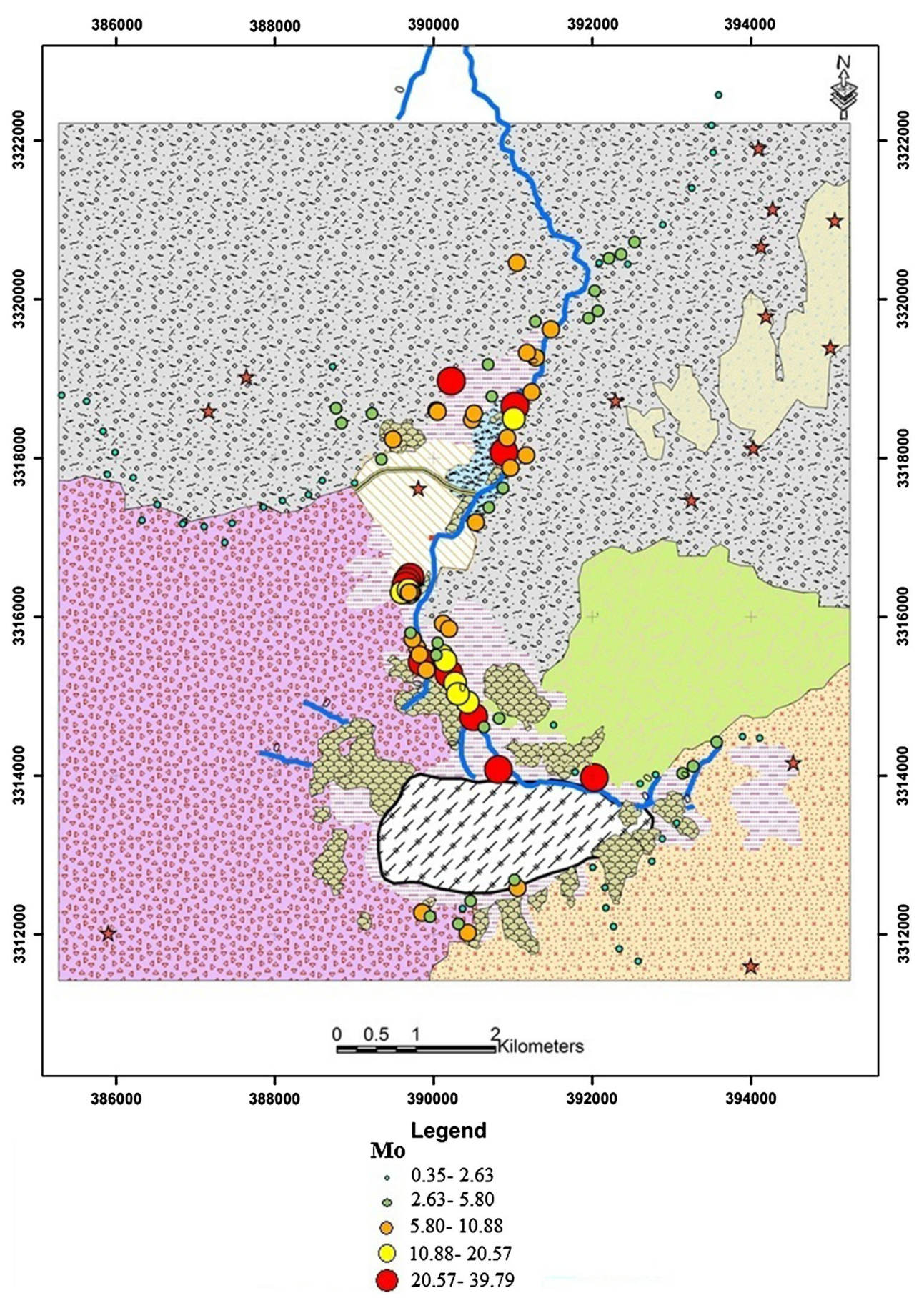

that represent the pessimistic, moderate and optimistic estimates are used to represent the opinions of experts about each parameter.

$a_{i j}=\left(\alpha_{i j}, \delta_{i j}, \gamma_{i j}\right)$
$\alpha_{i j}=\operatorname{Min}\left(\beta_{i j k}\right), \quad k=1, \ldots, n$ 

concentrations at Sarcheshmeh copper complex
Fig. 8 Map of variation in $\mathrm{Zn}$

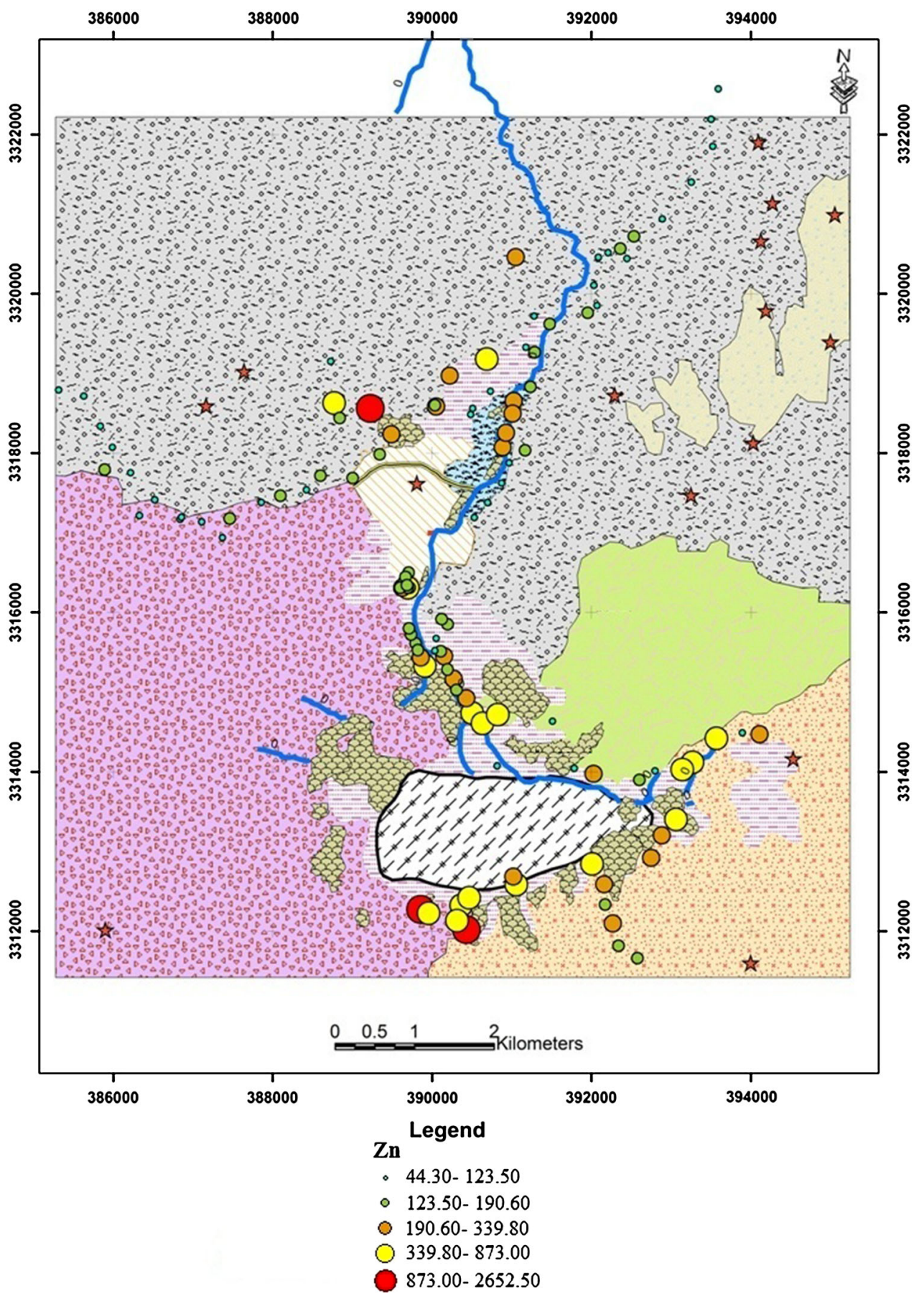

$\gamma_{i j}=\operatorname{Max}\left(\beta_{i j k}\right), \quad k=1, \ldots, n$

expert $k$ between parameters $i$ and $j$, and; $\lambda$ is the number of experts. (b) Following the above outlines, a fuzzy positive reciprocal matrix $\tilde{A}$ can be calculated:

$\tilde{A}=\left[\begin{array}{ccc}(1,1,1) & \left(\alpha_{12}, \delta_{12} \cdot \gamma_{12}\right) & \left(\alpha_{13}, \delta_{13}, \gamma_{13}\right) \\ \left(1 / \gamma_{12}, 1 / \delta_{12}, 1 / \alpha_{12}\right) & (1,1,1) & \left(\alpha_{23}, \delta_{23}, \gamma_{23}\right) \\ \left(1 / \gamma_{13}, 1 / \delta_{13}, 1 / \alpha_{13}\right) & \left(1 / \gamma_{23}, 1 / \delta_{23}, 1 / \alpha_{23}\right) & (1,1,1)\end{array}\right]$ 
Table 2 Selected metal concentrations in average continental shale and average continental crust

\begin{tabular}{llcc}
\hline Element & Average continental crust $^{\mathrm{b}}$ & Average continental shale $^{\mathrm{a}}$ & Average soil samples \\
\hline $\mathrm{Se}$ & 0.4 & 0.5 & 1.08 \\
$\mathrm{~Pb}$ & 14.8 & 20 & 127 \\
$\mathrm{Ni}$ & 40 & 68 & 27 \\
$\mathrm{Mo}$ & 2 & 3 & 7.1 \\
$\mathrm{Zn}$ & 65 & 95 & 252 \\
\hline
\end{tabular}

a Turekian and Wedepohl (1961)

b Wedepohl (1995)

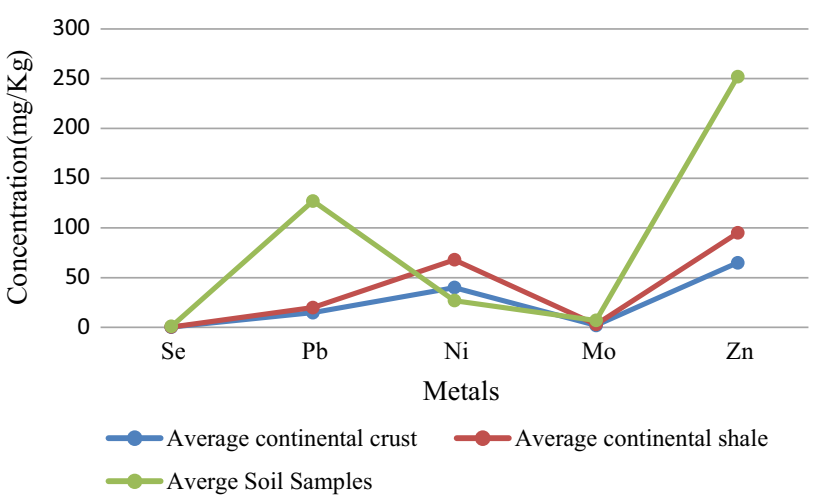

Fig. 9 A comparison of the mean concentrations of potentially toxic metals in soil samples at Sarcheshmeh copper complex with the average crust values for uncontaminated soils and average shale

Table 3 Contamination factors (CF) for metals in soils at Sarcheshmeh copper complex

\begin{tabular}{llllll}
\hline Baseline & \multicolumn{6}{l}{ Contamination Factor } \\
\cline { 2 - 6 } & $\mathrm{Se}$ & $\mathrm{Zn}$ & $\mathrm{Ni}$ & $\mathrm{Mo}$ & $\mathrm{Pb}$ \\
\hline CF (average continental crust) & 2.70 & 4.06 & 1.48 & 3.93 & 4.01 \\
CF (background) & 0.98 & 3.82 & 1.80 & 4.53 & 3.85 \\
Concentration (mg/kg) & & & & & \\
Average continental crust & 0.4 & 65 & 40 & 2 & 14.8 \\
Background & 1.1 & 66 & 15 & 1.03 & 31 \\
\hline
\end{tabular}

(c) The relative fuzzy weights of the evaluation factors are calculated

$$
\begin{aligned}
\tilde{Z} i & =\left[\tilde{a}_{i j} \ldots \tilde{a}_{i n}\right]^{1 / n}, \\
\tilde{W} i & =\tilde{Z} i(\tilde{Z} i \oplus \cdots \oplus \tilde{Z} n),
\end{aligned}
$$

where $\tilde{a}_{1} \otimes \tilde{a}_{2}=\left(\alpha_{1} \times \alpha_{2}, \delta_{1} \times \delta_{2}, \gamma_{1} \times \gamma_{2}\right)$. The symbol $\otimes$ denotes the multiplication of fuzzy numbers and the symbol $\oplus$ denotes the addition of fuzzy numbers. $\tilde{W}_{i}$ is arrow vector in consist of a fuzzy weight of the $i$ th factor $\tilde{W}_{i}=\left(\omega_{1}, \omega_{2}, \omega_{3}, \ldots \omega_{n}\right)$. Defuzzification (changing the fuzzy number to a usual number) is based on the geometric average method (Kaufman and Gupta 1988):

$\tilde{W} \boldsymbol{i}=\left(\Pi_{i=1}^{3} \omega_{j}\right)^{1 / 3}$.

\section{Risk assessment using FDAHP and SAW methodology} weighting of the criteria and then the simple additive weighting (SAW) method is applied to determine the highest pollution and critical risk among the metals in the soils under study. A comparison matrix of parameters based on each expert's opinion is required to establish the main pair-wise comparison matrix using the FDAHP method. Since there were 4 criteria and 6 experts, six $4 \times 4$ pair-wise comparison matrixes (Supplementary Tables 4-6) were established for the following calculations. The total weights of criteria are listed in Table 6.

Most of data in a multi-attribute decision-making (MADM) problem are unstable and changeable, then sensitivity analysis after problem solving can effectively contribute to making accurate decisions. This study provides a new method for sensitivity analysis of MADM problems so that by using it and changing the weights of attributes, one can determine changes in the final results of a decision-making problem. This analysis applied to simple
At this stage, FDAHP method is used to obtain final

Table 4 Calculation results of risk indicators for metals in soils at Sarcheshmeh copper complex

\begin{tabular}{llllll}
\hline Element & CF & EF & Classification of concentration factor & $i_{\text {geo }}$ & Intense pollution of the area on the basis of $I_{\text {geo }}$ \\
\hline $\mathrm{Se}$ & 0.98 & 1.51 & No concentration & $<0$ & No contamination \\
$\mathrm{Zn}$ & 3.82 & 2.88 & Medium (avg.) concentration & 0.32 & Uncontaminated-low contamination \\
$\mathrm{Ni}$ & 1.80 & 0.58 & Low concentration & $<0$ & No contamination \\
$\mathrm{Mo}$ & 4.53 & 2.02 & High concentration & 0.14 & Uncontaminated-low contamination \\
$\mathrm{Pb}$ & 3.85 & 6.98 & Medium (avg.) concentration & 1.47 & Low contamination \\
\hline
\end{tabular}


Table 5 The Saaty rating scale (1980)

\begin{tabular}{|c|c|c|}
\hline Importance & Definition & Explantation \\
\hline 1 & $\begin{array}{l}\text { Equal } \\
\text { importance }\end{array}$ & $\begin{array}{l}\text { Two factors contribute equally to the } \\
\text { objective }\end{array}$ \\
\hline 3 & $\begin{array}{l}\text { Somewhat } \\
\text { more } \\
\text { important }\end{array}$ & $\begin{array}{l}\text { Experience and judgement slightly } \\
\text { favor one over the other }\end{array}$ \\
\hline 5 & $\begin{array}{r}\text { Much more } \\
\text { important }\end{array}$ & $\begin{array}{l}\text { Experience and judgement strongly } \\
\text { favor one over the other }\end{array}$ \\
\hline 7 & $\begin{array}{l}\text { Very much } \\
\text { more } \\
\text { important }\end{array}$ & $\begin{array}{l}\text { Experience and judgement very } \\
\text { strongly favor one over the other. Its } \\
\text { importance is demonstrated in } \\
\text { practice }\end{array}$ \\
\hline 9 & $\begin{array}{l}\text { Absolutely } \\
\text { more } \\
\text { important }\end{array}$ & $\begin{array}{l}\text { The evidence favoring one over the } \\
\text { other is of the highest possible } \\
\text { validity }\end{array}$ \\
\hline $2,4,6,8$ & $\begin{array}{l}\text { Intermediate } \\
\text { values }\end{array}$ & When compromise is needed \\
\hline
\end{tabular}

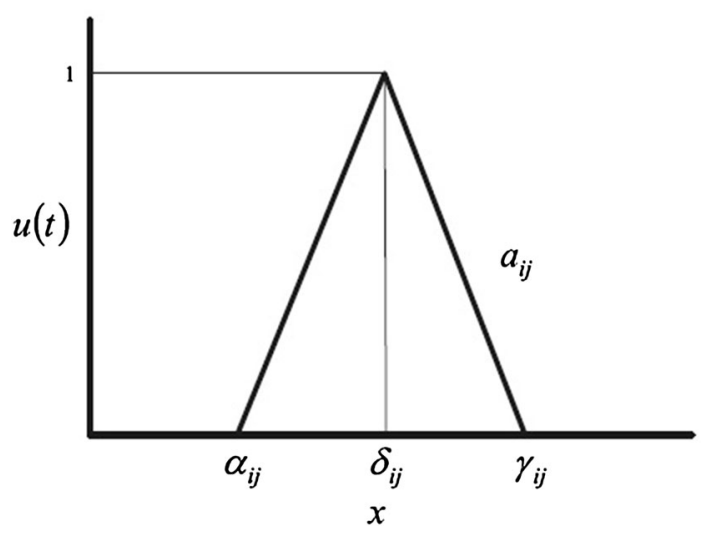

Fig. 10 The membership function of the fuzzy Delphi method

additive weighting (SAW) technique, one of the widely used multi-attribute decision-making techniques, and the formulas are obtained.

\section{SAW technique}

The SAW technique is one of the most used MADM techniques. It is simple and is the basis of most MADM techniques such as AHP and PROMETHEE that benefits from an additive property for calculating the final score of alternatives. This type of sensitivity analysis can be applied in MADM-related software for solving decision-making problems so by adding it to this software and by utilizing graphical capability of a computer, one can change the weight of one attribute arbitrarily and observe its effect on the final score and rank of alternatives, immediately. The following suggestions are proposed for future researches:
Table 6 Total weights of criteria resulted from FDAHP method

\begin{tabular}{ll}
\hline Risk assessment criteria & Total weight \\
\hline Contamination factor & 0.191 \\
Average concentration & 0.257 \\
Enrichment factor & 0.236 \\
Geoaccumulation index & 0.316 \\
\hline
\end{tabular}

- Evaluating the effect of changes in one element of the decision-making matrix on the final score of alternatives in the SAW technique.

- Studying the effect of simultaneously changes in the weight of one attribute and one element of decisionmaking matrix on the final score of alternatives in the SAW technique.

- Applying this type of sensitivity analysis for other techniques of MADM such as PROMETHEE and AHP.

In the SAW technique, the final score of each alternative for ranking is calculated as follows:

$A=\left\{\frac{\Sigma_{j} w_{j} \cdot r_{i j}}{\Sigma_{j} w_{j}}\right\}$,

where $r_{i j}$ are normalized values of decision matrix elements.

The vector for weights of attributes is obtained from following relation:

$A=\left\{\Sigma_{j} w_{j} \cdot r_{i j}\right\}$

wherein $W_{j}=\left(W_{1}, W_{2}, \ldots, W_{k}\right)$ weights are normalized and sum of them is 1 .

The SAW algorithm is summarized in two main steps (Tzeng and Huang 2011):

Step 1: Using a linear scaling of parameters by the relations 15 and 16 for indicators with positive and negative effects, respectively:

$n_{i j}=\frac{r_{i j}}{\max _{i}\left(r_{i j}\right)} ; X_{j}^{+}$

$n_{i j}=\frac{\min _{i}\left(r_{i j}\right)}{r_{i j}} ; X_{j}^{-} ; j \in j^{\prime}$.

Note that the effect is positive for all indices. This means that with increasing the amounts of these parameters for each element, the environmental risk increases. Therefore, Eq. 15 is used for data normalization.

$n_{i j}=\left[\begin{array}{cccc}0.000007 & 0.338 & 0.057 & 0.107 \\ 0.000007 & 0.511 & 1.000 & 0.028 \\ 0.095 & 0.143 & 0.231 & 0.004 \\ 1.000 & 0.368 & 0.117 & 1.000 \\ 0.218 & 1.000 & 0.052 & 0.504\end{array}\right]$


Table 7 The final score and risk ranking of contaminations

\begin{tabular}{lll}
\hline Risk & Score & Rank \\
\hline $\mathrm{Pb}$ & 0.47 & 2 \\
$\mathrm{Ni}$ & 0.63 & 1 \\
$\mathrm{Se}$ & 0.11 & 5 \\
$\mathrm{Mo}$ & 0.38 & 3 \\
$\mathrm{Zn}$ & 0.14 & 4 \\
\hline
\end{tabular}

If there is any qualitative attribute, we can use some methods for transforming qualitative variables to quantitative ones.

Step 2: Determining the final weight (score) of each option from Eq. 14 (Table 7)

In this step, the higher final score indicates the more critical conditions of the sampled element from the point of environmental contaminant risk. In other words, the ranking occurs on the basis of descending order of index A. According to Table 7, the risk ranking of metals is as $\mathrm{Ni}>\mathrm{Pb}>\mathrm{Mo}>\mathrm{Zn}>\mathrm{Se}$.

\section{Conclusions}

In this study, first, by determining risk evaluation indices such as contamination index, pollution load index, enrichment factor and geoaccumulation index, we set out to assess metals contamination ( $\mathrm{Mo}, \mathrm{Zn}, \mathrm{Se}, \mathrm{Ni}$ and $\mathrm{Pb}$ ) in Sarcheshmeh copper complex soils area. Then, by collecting expert opinions on the relative importance of each of the indicators mentioned in the environmental contamination risk of metals, through final weighting of the indices using Fuzzy Delphi Analytic Hierarchy Process (FDAHP), ranking and clustering of metals in the soils of the studied area was performed using the simple additive weighting (SAW) method. The diversity of pollutants in the soil, along with the need to apply appropriate environmental measures to reduce the risk and irreversible negative consequences on the environment, led to this contaminant evaluation for a successful risk management process. The comparison of the metals concentration average and the toxic potential in the soil samples has shown an average with respect to the world average for the uncontaminated soil amounts and shale. The conclusion from the calculation of the concentrated factor, for some of the samples shows that the average of the lead, zinc and Mo elements stations are more than the background values and the unnatural metal concentration is covered under the studied area. In this paper, the SAW method has been investigated as a multi-attribute decision-making (MADM) method in contamination risk ranking due to metals in the soil of the Sarcheshmeh copper mine areas. With respect to the kind, quality criteria, selected slightly principle and understanding of risk assessment, data acquired for weighting indices or final score which can be considered for the contaminant risk indices of metals. The more the index for a particular place is bigger the more a sampling area has been done, and the more the criticism of the metals of this particular area is exposed at open risk. Therefore, the obtained index can be used as a criterion for risk assessment and ranking of their criticality. With this technique, one fact which can easily be observed is that the scientific and accurate possibility of ranking has been obtained. Based on the results, $\mathrm{Ni}, \mathrm{Pb}, \mathrm{Mo}, \mathrm{Zn}$ and Se showed the greatest level of contamination and criticality. Project management will be capable of programming a timely and suitable response to these risks by identifying risk factors and their contamination level, and better reducing the risk of down-gradient contamination.

Acknowledgments The authors would like to thank the National Iranian Copper Industries Company (NICICO), research and development unit, for supporting this research. The contribution of Adonis Fard Mousavi is appreciated.

Open Access This article is distributed under the terms of the Creative Commons Attribution 4.0 International License (http:// creativecommons.org/licenses/by/4.0/), which permits unrestricted use, distribution, and reproduction in any medium, provided you give appropriate credit to the original author(s) and the source, provide a link to the Creative Commons license, and indicate if changes were made.

\section{References}

Abrahim GMS, Parker RJ (2008) Assessment of heavy metal enrichment factors and the degree contamination in marine sediments from Tamaki. Estuary, Auckland, New Zealand. Environ Monit Assess 136:227-238

Adama P, Arienzo M, Imporato M, Noimo D, Nardi G, Stanzione D (2005) Distribution and partition of metals in surface and subsurface sediments of Naples city port. Chemosphere 61:800-809

Adomako D, Nyarko BJB, Dampare SB, Serfor-Armah Y, Osae S, Fianko JR, Akaho EH (2008) Determination of toxic elements in waters and sediments from River Subin in the Ashanti Region of Ghana. Environ Monit Assess 141:165-175

Adriano DC (1986) Trace elements in the terrestrial environment. Springer, New York

Albanese S, Cicchella D, De Vivo B, Lima A (2007) Geochemical background and baseline values of toxic elements in stream sediments of Campania region (Italy). J Geochem Explor 93:21-34

Audry S, Schafer J, Blanc G, Jouanneau JM (2004) Fifty-year sedimentary record of heavy metal pollution $(\mathrm{Cd}, \mathrm{Zn}, \mathrm{Cu}, \mathrm{Pb})$ in the Lot River reservoirs (France). Environ Pollut 132(3):413-426

Bermejo Santos JC, Beltran R, Gomez Araiza JL (2003) Spatial variations of metals contamination in sediments from Odiel River (southwest Spain). Environ Int 29(1):69-77

Bounessah M, Atkin BP (2003) An application of exploratory data analysis (EDA) as a robust non-parametric technique for geochemical mapping in a semi-arid climate. Appl Geochem 18:1185-1195 
Bourennane H, Douay F, Sterckeman T, Villanneau E, Ciesielski H, King D, Baize D (2010) Mapping of anthropogenic trace elements inputs in agricultural topsoil from Northern France using enrichment factors. Geoderma 157:165-174

Buat-Menard P, Chesselet R (1978) Variable influence of the atmospheric flux on the trace metal chemistry of oceanic suspended matter. Earth Planet Sci Lett 42:399-411

Burgos P, Madejón E, Pérez de Mora A, Cabrera F (2005) Spatial variability of the chemical characteristics of a trace-elementcontaminated soil before and after remediation. Geoderma 130:157-175

Cai L, Xu Z, Ren M, Guo Q, Hu X, Hu G, Wan H, Peng P (2012) Source identification of eight hazardous metals in agricultural soils of Huizhou, Guangdong Province, China. Ecotoxicol Environ Saf 78:2-8

Cambier P (1997) Evaluation of the mobility of toxic elements in contaminated soils. Anal Mag 25:35-38

Chen CW, Kao CM, Chen CF, Dong CD (2007) Distribution and accumulation of metals in the sediments of Kaohsiung Harbor, Taiwan. Chemosphere 66(8):1431-1440

Chester R, Stoner JH (1973) Pb in particulates from the lower atmosphere of the eastern Atlantic. Nature 245:27-28

Cicchella D, De Vivo B, Lima A, Albanese S, Mc Gill RAR, Parrish RR (2008) Heavy metal pollution and Pb isotopes in urban soils of Napoli, Italy. Geochem Explor Environ Anal 8:103-112

De Vries W, Vel E, Reinds GJ, Deelstra H, Klap JM, Leeters EEJM, Hendriks CMA, Kerkvoorden M, Landmann G, Herkendell J, Haussmann T, Erisman JW (2002) Intensive monitoring of forest ecosystems in Europe 1. Objectives, setup and evaluation strategy. Forest Ecol Manag 5890:1-19

Dijkstra EA (1998) Micromorphological study on the development of humus profiles in heavy metal polluted and non-polluted forest soils under Scots pine. Geoderma 82:341-358

Ferguson C Kasamas H (1999) Risk Assessment for contaminated sites in Europe: policy framework, vol 2. LQM Press, Nottingham

Ghrefat H, Yusuf N (2006) Assessing Mn, Fe, Cu, Zn and Cd pollution in bottom sediments of Wadi AL- Arab Dam, Jordan. Chemosphere 65:2114-2121

Giaccio L, Cicchella D, De Vivo B, Lombardi G, De Rosa M (2012) Does metals pollution affects semen quality in men? A case of study in the metropolitan area of Naples (Italy). J Geochem Explor 112:218-225

Guillén MT, Delgado J, Albanese S, Nieto JM, Lima A, De Vivo B (2011) Environmental geochemical mapping of Huelva municipality soils (SW Spain) as a tool to determine background and baseline values. J Geochem Explor 109:59-69

Guillén MT, Delgado J, Albanese S, Nieto JM, Lima A, De Vivo B (2012) Metals fractionation and multivariate statistical techniques to evaluate the environmental risk in soils of Huelva township (SW Iberian Peninsula). $\mathrm{J}$ Geochem Explor 119-120:32-43

Hakanson L (1980) Ecological risk index for aquatic pollution control, a sedimentological approach. Water Res 14:975-1001

Han Y, Du P, Cao J, Posmentier ES (2006) Multivariate analysis of heavy metal contamination in urban dusts of Xi'an, Central China. Sci Total Environ 355:176-186

Hawkes HE, Webb JS (1962) Geochemistry in mineral exploration. Harper and Row, New York

Hayaty M, Tavakoli Mohammadi MR, Rezaei A, Shayestehfar MR (2014) Risk Assessment and Ranking of metals Using FDAHP and TOPSIS. Mine Water Environ 33(2):157-164

Hoseinie SH, Ataei M, Osanloo M (2009) A new classification system for evaluating rock penetrability. Int J Rock Mech Min Sci 46:1329-1340
Hwang CL, Yoon K (1981) Multiple attribute decision making: methods and applications. Springer, Berlin

Kaufmann A, Gupta MM (1988) Fuzzy mathematical models in engineering and management science. North-Holland, Amsterdam

Li X, Feng L (2012) Multivariate and geostatistical analyzes of metals in urban soil of Weinan industrial areas, Northwest of China. Atmospheric Environ 47(0):58-65

Li X, Lee SL, Wong SC, Shi W, Thornton I (2004) The study of metal contamination in urban soils of Hong Kong using a GIS-based approach. Environ Pollut 129:113-124

Liu YC, Chen CS (2007) A new approach for application of rock mass classification on rock slope stability assessment. Eng Geol 89:129-143

Lu XW, Wang LJ, Lei K, Huang J, Zhai YX (2009) Contamination assessment of copper, lead, zinc, manganese and nickel in street dust of Baoji, NW China. J Hazard Mater 161:1058-1062

Martínez J, Llamas J, De Miguel E, Rey J, Hidalgo MC (2007) Determination of the geochemical background in a metal mining site: example of the mining district of Linares (South Spain). J Geochem Explor 94:19-29

Muller G (1979) Schwermetalle in den sedimenten des Rheins Veranderungen seit 1971. Umschau 79(24):778-783

Müller G (1969) Index of geoaccumulation in the sediments of the Rhine River. GeoJournal 2:108-118

Munendra S, Muller G, Sinhg B (2002) Metals in freshly deposited stream sediments of rivers associated with urbanization of the Ganga plain, India. Water Air Soil Pollut 141:35-54

Plant J, Smith D, Smith B, Williams L (2001) Environmental geochemistry at the global scale. Appl Geochem 16:1291-1308

Qishlag A, Moore F, Forghani G (2007) Impact of untreated wastewater irrigation on soils and crops in Shiraz suburban area, SW Iran. Environ Monit Assess 149:254-262

Reddy M, Basha S, Sravan Kumar VG, Joshi HV, Ramachandraiah G (2004) Distribution, enrichment and accumulation of metals in coastal sediments of the Alang- Sosiya ship scrapping yard, India. Mar Pollut Bull 48:1055-1059

Reimann C, Filzmoser P, Garrett RG (2005) Background and threshold: critical comparison of methods of determination. Sci Total Environ 346:1-16

Saaty TL (1980) The analytic hierarchy process. McGraw-Hill, New York

Salomons W, Förstner U (1984) Metals in the hydrocycle. Springer, Berlin

Selvaraj K, Rom Mohan V, Szefer P (2004) Evaluation of metal contamination in coastal sediments of the Bay of Bengal, India; geochemical and statistical approaches. Mar Pollut Bull 49:174-185

Shayestehfar MR, Rezaei A (2010) Methodology presentation in decreasing the environmental of Sarcheshmeh copper mine with the help of geochemical data. In: Proceedings of 27th Symposium on Geosciences, Tehran, pp 254-264

Sheppard DS, Claridge GGC, Campbell IB (2000) Metal contamination of soils at Scott base, Antarctica. Appl Geochem 15(4):513-530

Taylor SR (1964) The abundance of chemical elements in the continental crust-a new table. Geochimica Cosmochimica Acta 28:1273-1285

Tlili-Zrelli B, Gueddari M, Bouhlila R (2013) Geochemistry and quality assessment of groundwater using graphical and multivariate statistical methods. A case study: grombalia phreatic aquifer (NE). Arabian J Geosciences 6(9):3545-3561

Turekian KK, Wedepohl DH (1961) Distribution of the elements in some major units of the earth's crust. Bullet Geol Soc Am 72:175-192

Tzeng GH, Huang JJ (2011) Multiple attribute decision making: methods and applications. Chapman and Hall/CRC 
Vardes J, Var Gas G, Sifeddine M (2005) Distribution and enrichment evaluation of metals in Mejillones Bay (23 AS), Northern Chile: geochemical and statistical approach. Mar Pollut Bull 50:1558-1568

Wedepohl KH (1995) The composition of the continental crust. Geochim Cosmochim Acta 59:1217-1232

Zhou X, Xia B (2010) Defining and modeling the soil geochemical background of metals from the Hengshi River watershed (southern China): integrating EDA, stochastic simulation and magnetic parameters. J Hazard Mater 180:542-551

Zoller WH, Gladney ES, Duce RA (1974) Atmospheric concentrations and sources of trace metals at the South Pole. Science 183:199-201 